\title{
Pneumocystis jirovecii pneumonia in COVID-19: an overlooked clinical entity- Response to "Pneumocystis pneumonia risk among viral acute respiratory distress syndrome related or not to COVID 19"
}

\author{
Antonio Riccardo Buonomo, Giulio Viceconte* ${ }^{*}$ and Ivan Gentile
}

\section{To the editor,}

We read with great interest the article published in Critical Care by Razazi et al. reporting no cases of Pneumocystis jirovecii pneumonia (PJP) among intubated patients with acute respiratory distress syndrome (ARDS) secondary to COVID-19 (C-ARDS) [1].

The authors compared these results with a historical cohort of non-COVID-19 ARDS (NC-ARDS). They showed a higher incidence of proven PJP and PCR positivity (without a diagnosis of PJP) in respiratory samples in NC-ARDS than in C-ARDS $(0.05 \%$ and $13 \%$ vs $0 \%$ and $0 \%$, respectively) [1].

However, patients in study by Razazi et al. are enrolled during the first period of pandemic, when dexamethasone was not strongly recommended and, surprisingly, they found a more profound lymphopenia in NC-ARDS. Moreover, in NC-ARDS group $82 \%$ of enrolled patients were immunocompromised compared to $13 \%$ of C-ARDS [1].

Conversely, we have published 5 cases of proven PJP in immunocompetent hosts in late phase of COVID-19 disease $[2,3]$. According to EORTC/MSGERC diagnostic criteria, we observed that the use of steroids was the most frequent host factor that predispose to PJP [4].

This comment refers to the article available online at https://doi.org/10.1186/ s13054-021-03767-3.

*Correspondence: giulio.viceconte@gmail.com

Department of Clinical Medicine and Surgery, University of Naples

"Federico II", Via Sergio Pansini n.5, 80130 Naples, Italy
Moreover, Razazi et al. showed that the two proven PJP diagnosis in NC-ARDS cohort had Beta-D Glucan assay $(\mathrm{BDG})>80$, while in our experience we documented negative BDG in all the proven cases.

In the end, we think that the absence of PJP cases in C-ARDS cohort may have been influenced by the phase of COVID-19 clinical course and lower dosage of steroids administrated, while the higher prevalence of PJP diagnosis and qPCR positivity in NC-ARDS cohort should be led back to the high prevalence of immunocompromised patients enrolled.

Therefore, since either lymphopenia or steroidal treatment are strongly associated with the risk of PJP development, further studies are needed to detect any other risk factor for developing PJP in COVID-19 and to design any potential prophylactic strategies. Nevertheless, it is noteworthy that BDG assay has a high negative predictive value in HIV positive patients for PJP diagnosis, while it is less clear the real power of this test in other settings such as immunocompetent patients and COVID-19.

In conclusion, the pathogenesis of PJP in late COVID19 and the role of BDG and of PCR in predicting development of PJP must be further investigated, and PJP should be taken into account in differential diagnosis of respiratory relapse in late COVID-19 by obtaining invasive samples (bronchoalveolar lavage), since BDG seems to have a low negative predictive value in this setting.

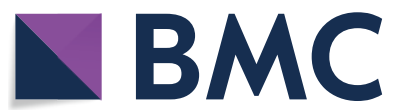

(c) The Author(s) 2021. Open Access This article is licensed under a Creative Commons Attribution 4.0 International License, which permits use, sharing, adaptation, distribution and reproduction in any medium or format, as long as you give appropriate credit to the original author(s) and the source, provide a link to the Creative Commons licence, and indicate if changes were made. The images or other third party material in this article are included in the article's Creative Commons licence, unless indicated otherwise in a credit line to the material. If material is not included in the article's Creative Commons licence and your intended use is not permitted by statutory regulation or exceeds the permitted use, you will need to obtain permission directly from the copyright holder. To view a copy of this licence, visit http://creativecommons.org/licenses/by/4.0/. The Creative Commons Public Domain Dedication waiver (http://creativeco mmons.org/publicdomain/zero/1.0/) applies to the data made available in this article, unless otherwise stated in a credit line to the data. 


\section{Authors' response}

\section{Romain Arrestier, Armand Mekontso-Dessap, Francoise Botterel and Keyvan Razazi}

\section{To the Editor,}

We thank Buonomo and colleagues for their comment that our finding of a very low risk of Pneumocystis pneumonia in COVID-19 patients with acute respiratory distress syndrome (ARDS) stands in contrast to their experience on Pneumocystis pneumonia in COVID-19 patients.

We agree that enrolment of patients during the first wave may be a limit of our study because of a lower use of steroid therapy. To explore further this potential bias, we analyzed 239 consecutive COVID-19 patients, hospitalized in our intensive care unit during the following waves from May 26th 2020 to April 11th 2021 (Anticovid study Clinical trials NCT04433105). All were treated with steroids, 39 (16.3\%) with tocilizumab and 29 (12.1\%) were immunocompromised.

Of these, 73 had a Pneumocystis examination, including 131 PCR and 107 direct examinations (43 May Grunwald Giemsa stainings and 64 Grocott colorations) which were all negative. Only three patients $(4 \%)$ had a positive PCR with a cycle threshold range of 35.5-37. All were classified as Pneumocystis colonization. Two of them did not have any pre-existing risks factors besides 10 days of steroid for COVID-19 and had a negative $\beta$-D-glucan. One patient with liver transplantation and long-term steroid therapy and calcineurin inhibitor treatment had a positive PCR with only one low titer positive $\beta$-D-glucan $(178 \mathrm{pg} / \mathrm{mL})$; he was classified as Pneumocystis colonization because his state improved without trimethoprimsulfamethoxazole treatment.

The five patients described by Gentile and al [2] were very different from those of our cohort. None of them had ARDS requiring invasive mechanical ventilation, and they were surprisingly all treated with steroids with a very high cumulative dose of steroid (range from 400 to $1150 \mathrm{mg}$ prednisone equivalent) and a longer duration than recommended.

The authors did not specify if they received a trimethoprim-sulfamethoxazole prophylaxis. In our intensive care unit, we systematically prescribed a prophylaxis as suggested if the steroid dose is higher than $0.3 \mathrm{mg} / \mathrm{kg} / \mathrm{d}$ equivalent prednisone for at least 3 weeks, whatever the disease $[5,6]$. This could explain the difference between our observation and those from Gentile and al.

In a recent meta-analysis, a negative BDG test to 'rule out' PJP with $95 \%$ certainty (post-test probability of $5 \%$ ) requires that the pre-test probability be low $(<20 \%)$, as in COVID-19 patients [7].
Altogether, these data confirm that even when steroid therapy was the standard of care, Pneumocystis pneumonia risk is very low among patients with COVID-19 related ARDS even in immunocompromised patients.

\author{
Acknowledgements \\ Not applicable. \\ Authors' contributions \\ All the authors have equally contributed. \\ Funding \\ No funding sources have been used. \\ Availability of data and materials \\ Not applicable.

\section{Declarations} \\ Ethics approval and consent to participate \\ Not applicable. \\ Consent for publication \\ Not applicable. \\ Competing interests \\ Authors have no competing interests to disclose.
}

Received: 9 November 2021 Accepted: 10 November 2021

Published online: 06 December 2021

References

1. Razazi K, Arrestier R, Haudebourg AF, Botterel F, Mekontso DA. Pneumocystis pneumonia risk among viral acute respiratory distress syndrome related or not to COVID 19. Crit Care. 2021;25(1):1-4. https://doi.org/10.1186/ s13054-021-03767-3.

2. Gentile I, Viceconte G, Lanzardo A, Zotta I, Zappulo E, Pinchera B, et al. Pneumocystis jirovecii pneumonia in non-HIV patients recovering from COVID-19: a single-center experience. Int J Environ Res Public Health. 2021;18:11399.

3. Viceconte G, Buonomo AR, Lanzardo A, Pinchera B, Zappulo E, Scotto R, et al. Pneumocystis jirovecii pneumonia in an immunocompetent patient recovered from COVID-19. Infect Dis. 2021;53(5):382-5. https://doi.org/10. 1080/23744235.2021.1890331.

4. De Pauw B, Walsh TJ, Donnelly JP, Stevens DA, Edwards JE, Calandra T, et al. Revised definitions of invasive fungal disease from the European Organization for Research and Treatment of Cancer/Invasive Fungal Infections Cooperative Group and the National Institute of Allergy and Infectious Diseases Mycoses Study Group (EORTC/MSG) Consensus Group. Clin Infect Dis. 2008;46(12):1813-21.

5. Yale SH, Limper AH. Pneumocystis carinii pneumonia in patients without acquired immunodeficiency syndrome: associated illness and prior corticosteroid therapy. Mayo Clin Proc. 1996;71:5-13.

6. Donnelly JP, Chen SC, Kauffman CA, Steinbach WJ, Baddley JW, Verweij PE, et al. Revision and update of the consensus definitions of invasive fungal disease from the European Organization for Research and Treatment of Cancer and the Mycoses Study Group Education and Research Consortium. Clin Infect Dis. 2019;71:1367-76.

7. Del Corpo O, Butler-Laporte G, Sheppard DC, Cheng MP, McDonald EG, Lee TC. Diagnostic accuracy of serum (1-3)- $\beta$-D-glucan for Pneumocystis jirovecii pneumonia: a systematic review and meta-analysis. Clin Microbiol Infect. 2020;26:1137-43.

\section{Publisher's Note}

Springer Nature remains neutral with regard to jurisdictional claims in published maps and institutional affiliations. 